\title{
Patterns of Cataract in Patients Reporting to Christian Hospital, Taxila, Pakistan
}

\author{
Arnold Rafiq ${ }^{1}$ and Noureen Latif ${ }^{2 *}$ \\ ${ }^{1}$ Hospital pharmacist at Christian Hospital, Taxila, Pakistan \\ ${ }^{2}$ Lecturer at Sarhad University, Islamabad campus, Pakistan
}

Received: October 25, 2017; Published: November 07, 2017

*Corresponding author: Noureen latif, Lecturer at Sarhad University, Islamabad campus, Pakistan

\begin{abstract}
Introduction: Cataract is cause of blindness in about $5 \%$ of the population in America and twenty million throughout the world. There are many reasons behind it and they can be controlled at the early age to prevent blindness at the old age.

Objectives: The main purpose of this dissertation was to study patterns of cataract in patients reporting to Christian Hospital, Taxila.

Methodology: The data was collected through self-designed questionnaire.

Results: Patients reporting to Christian Hospital, Taxila who were diagnosed cataract were approached and asked questions about cataract, their medical history and difficulty they were facing due to this illness. Data from 120 persons was collected. $47.5 \%$ of the respondents came due to poor vision in left eye. $7.5 \%$ of the respondents had poor vision of both eyes. $59.17 \%$ of the respondents had history of hypertension, $51.67 \%$ had history of diabetes, $17.50 \%$ had history of obesity. $55 \%$ of the respondents had history of smoking, all of them were males. $4.2 \%$ of the respondents were using statins. $4.2 \%$ of the respondents had previous eye injury and $17.5 \%$ of the respondents had previous eye surgery and $18.3 \%$ of the respondents had family history of cataract. Majority was facing this situation about 1-3 years before. $84.2 \%$ of the respondents had age related cataract and $9.2 \%$ of the respondents had previous eye injury.
\end{abstract}

Conclusion: In the present study most of the respondents were suffering from age related cataract. Nuclear cataract was more prevalent among th

Keywords: Patterns; Cataract; Patient; Smoking

\section{Introduction}

Cataract is a haziness (clouding) of the eye lens that leads to a decrease or in severe condition loss of eye vision. One or both of the eyes can be affected by this condition. It does not develop at once rather it grows and develops slowly. Symptoms of this condition may be:

a. fading of colors they may become discolored if prolonged

b. Blurred or fizzy vision,

c. Corona around the light,

d. Trouble while sighting bright lights

e. Difficulty in sighting in night [1].

All these symptoms can lead to difficulty car driving. This may result in trouble driving, book reading, perceiving or recognizing faces. Difficulty in vision increases the risk of falls and depression.
$33 \%$ of the vision impairment is the results of the cataract worldwide [1]. One of the main reason of cataracts is
i. $\quad$ Aging
ii. Trauma or radiation exposure,
iii. can be present at birth,
iv. after an eye surgery as a problem of secondary issue [2].

Risk factors may include [3]:
A. Diabetes,
B. Hypertension,
C. Obesity,
D. Smoking,
E. Use of corticosteroids for long time, 
F. Use of statins (reduce cholesterol).

G. Eye inflammation

H. Ulttraviolet radiation,

I. Previous eye surgery,

J. Hormone replacement therapy,

K. Alcohol consumption,

L. Prolonged myopia,

M. Inherited.

Cataract is cause of blindness in about $5 \%$ of the population in America and twenty million throughout the world. In developing countries 10-40 children/100,000 suffer from cataract and in developed countries 1-4 children/100,000 [4]. Due to cataract it becomes tough to see in low light. It creates ring around dark lights. It may also become impressive to see. It creates a yellow or brown distort around anything that is viewed. It causes colors to become bleached. Cataract does not spread from one eye to another eye. The destructive eyesight evolves slowly. It takes time. Cataract becomes worse and worse if it is not treated. The severity of cataracts increases. It is rose complications on reading and writing. Surgery is wanted to eradicate the lens that is affected. Surgery also altered the affected lens. Cataract appears usually in the individuals of older age. It is very common in older individuals. Because of cataract, large numbers of people are facing blindness. It is at global level. The rate of blindness is increasing day by day [5]. There is no accessibility of surgery of cataract as spread more broadly. This is in the developing countries. It has been proposed that the number of blindness due to cataract has been reached more than 39 million [6].

It will be in the year 2025. This has been proposed by the recognizing of involvements that delay the evolvement or advancement of cataracts [7]. It has been also proposed by the projection of population. Surgical involvement is very limited in the developing countries [8]. This limitation of surgical involvement causes many troubles and complications in the treatment of cataract blindness. It has been proposed that cataract has become the third leading cause of blindness. It has become in the United States [9]. There is more than $8 \%$ of blindness in United States. The preponderance of blindness that occurred due to cataract was more than 13 per 100,000. The incidence of blindness occurred due to cataract was more than 1.5 per 100,000. It has been accounted in 1970. Due to operations of cataract, many influences have been occurred. It has been recorded that cataract reduced since 1970 in developed countries [10]. It has been recorded freshly that the leading cause of blindness is cataract due to non-operated age related cataract. It has been pointed that the influences in age related lens were more than $40 \%$ of people with the age from 52 to 64 .

The preponderance of these influences increased to more than $90 \%$ for people age from 75 to 85 . Age related cataract is ranged from $4 \%$ to $50 \%$ from the age 52 to 64 and 75 to 85 respectively
[11]. Cataract appears in the people of age 65 which is rising to more than $60 \%$ in the age of 85 in United Kingdom. People with age 65 are suffering from cataracts. Its rate is $20 \%$. It is $60 \%$ in the age 85 in France [12]. It has been expressed that the preponderance of cataract becoming doubles in Australia. It is becoming double with each decade of age after 40 years [13]. Almost every person with age 90 is facing cataract. Same incidence and preponderance of cataract has been expressed by the developed countries [14]. As the people are living long age so the preponderance of cataract is on the peak. It has become usual in these days. The record has been proposed freshly that cataracts appeared in more than 21 million adults of age 40. This rate will become double in year 2020 [15]. Data of incidence are accessible for cataract that is age related cataract. They are just few incidence data. The preponderance data of age-specific has been used by many to record incidence rates for lens opacities and for cataract for 5 years. The 5 -year incidence records for ages, for lens opacities are as followed:
a. Age 55 was $10 \%$,
b. Age 60 was $16 \%$,
c. Age 65 was $23 \%$,
d. Age 70 was $31 \%$,
e. Age75 was $37 \%$ [16].

The 5-year incidence records for ages, for cataract, the corresponding incidence records were 1, 2, 5, 9, and 15\% . These records show that the lens opacities are not revocable. They also shows that the lens opacities not attended by a differential mortality. The incidence rate reached to more than $80 \%$ for persons. The age is from 70 to 74 at baseline [17]. Age that is increasing is the major risk factor for age related cataracts. It has been proposed that the preponderance of cataract blindness increased. It has been also studied that the preponderance of cataract rose from $4 \%$ at age 52 64 . It is $50 \%$ at age $75-85$. More than $90 \%$ of person ages from 75 to 85 have age-related lens influences. The associated proof from many studies proposes a minor excess risk of cataract for women compared with men. An extensive risk of cortical cataract may describe the 10-20\% excess risk of cataract among women [18]. It has been proposed that cortical and nuclear cataracts are more usually commence in blacks than whites. It has been proposed that cataracts are the leading cause of blindness in blacks.

It has been studied that an extensive preponderance of cataract in tropical regions compared with non tropical regions are complex to calculate due to variations in survey methodology [19]. However, preponderance rates modified for age. It has been proposed an almost threefold reach in the preponderance of cataract at a level of $185 \mathrm{~m}$ compared with locations at more than $1,000 \mathrm{~m}$. In this study, due to tall neighboring mountains, extensive ascensions had less sunlight than lower ascensions. There was a strong positive combination between increasing hours of sunlight exposure and cataract [20]. Cataracts are the most common cause of destruct vision at global level. Cataracts particularly affect populations in evolving countries. They cause blindness. The study has been 
expressed in India that the preponderance of cataracts is three times greater than in the United States. The preponderance rate is $82 \%$ of Indians [21]. It is from the age 75 to 83 years. They are suffered by cataracts. In US only $46 \%$ of people are suffered from cataracts from age 75 to 83 years. It has been recorded that the cataract will increase in the evolving countries. The population increases will be the extensive. The people with the age 65 are increasing day by day. Due to the increase of this day by day, the incidence of cataract will appear. Then there will be surgery of cataract need [22].

\section{Materials and Methods}

It was a cross-sectional descriptive study done in Christian Hospital, Taxila Pakistan. The objectives of the study were to study the patterns of cataract, to find the causes of cataract and to collect the medical history of the patients. Study population was the patients reporting to Christian Hospital, Taxila. Convenient sampling technique was used to data collection. A self structured questionnaire was used as a data collection tool. Study duration was 2 months and sample size was $n=120$. A pilot study was done on 12 patients to assess the language and accuracy of the questionnaire. After that necessity changes were made in it and final questionnaire was designed. After collecting the data, all the variables were coded and data was entered in to SPSS version 20 software and was analyzed for the result. An informed written consent was taken from the participants before filling all the information on the questionnaire. A permission letter from the Christian Hospital, Taxila was taken before starting the study to collect data.

\section{Results}

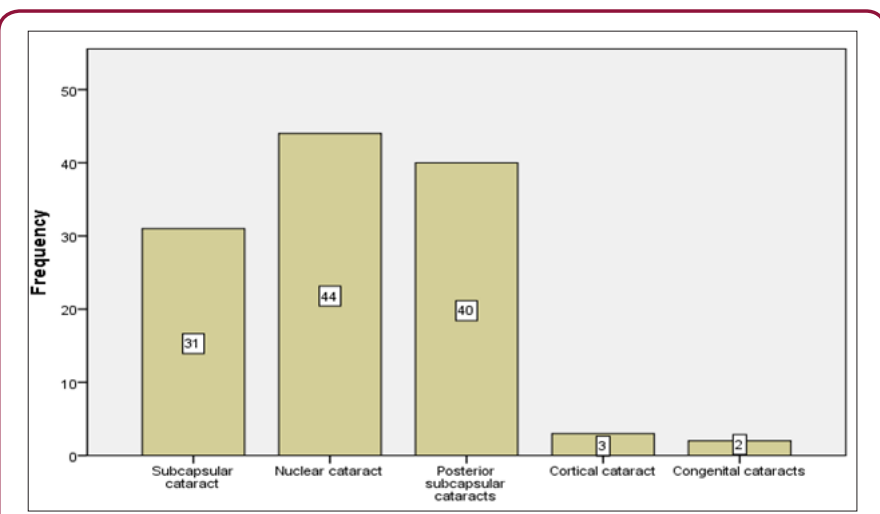

Figure 1: Type of cataract diagnosed.

Table 1: Medical history of the respondents.

\begin{tabular}{|c|c|c|c|}
\hline Sr. & History of & Yes $(\%)$ & No (\%) \\
\hline 1 & Hypertension & $71(59.2)$ & $49(40.8)$ \\
\hline 2 & Diabetes & $62(51.33)$ & $48(48.33)$ \\
\hline 3 & Obesity & $21(17.50)$ & $99(82.50)$ \\
\hline 4 & Smoking & $66(55.00)$ & $54(45.00)$ \\
\hline 5 & $\begin{array}{c}\text { Use of statins for } \\
\text { cholesterol reduction }\end{array}$ & $5(4.2)$ & $115(95.8)$ \\
\hline 6 & Previous eye injury & $5(4.2)$ & 115 (95.8) \\
\hline 7 & Previous eye surgery & $21(17.5)$ & $99(82.5)$ \\
\hline 8 & $\begin{array}{c}\text { Any family history of } \\
\text { cataract }\end{array}$ & $22(18.3)$ & $98(81.7)$ \\
\hline
\end{tabular}

120 persons were interviewed on the basis of convenient sampling. $n=31(25.85 \%)$ were females and $n=89$ (74.14\%) were males. Mean age of the respondents was $74.5 \pm .04$ years. Minimum and maximum age was found to be 20 and 89 years respectively. Majority of the patients were of the age group of $60-79$ years $(n=68,56.7 \%)$ and were illiterate $(n=49$ out of 120$) . n=84(70.0 \%)$ belonged to low socioeconomic status. $n=57$ came to hospital due to poor vision in left eye, $n=54$ had poor vision in right eye and $\mathrm{n}=9$ had poor vision in both eyes. Further results are given below (Tables 1,2).

Table 2: Reason of cataract.

\begin{tabular}{|c|c|c|}
\hline & Frequency & Percent (\%) \\
\hline Age related & 101 & 84.2 \\
\hline Obesity & 2 & 1.7 \\
\hline Statins (medicine) & 2 & 1.7 \\
\hline Previous eye injury & 11 & 9.2 \\
\hline Congenital & 4 & 3.3 \\
\hline Total & 120 & 100.0 \\
\hline
\end{tabular}

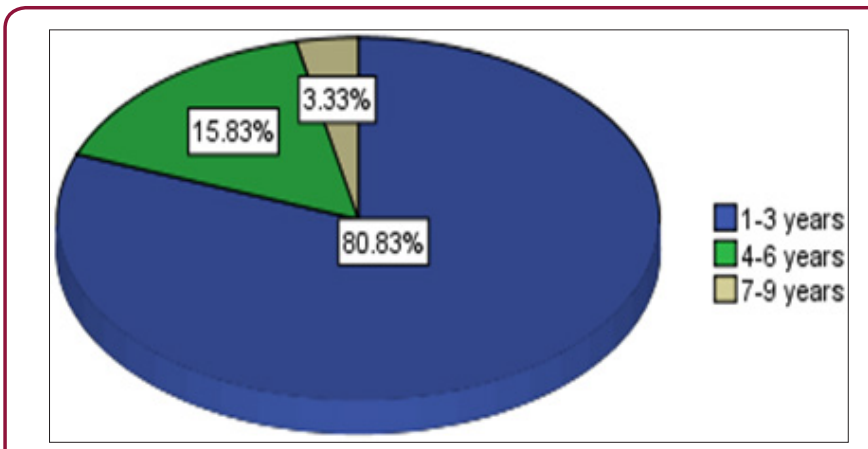

Figure 2: Duration of having cataract condition.

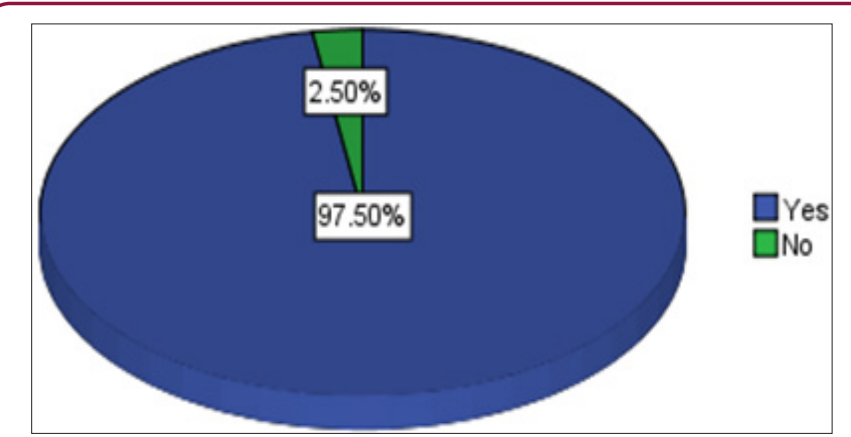

Figure 3: Suggestion of surgery.

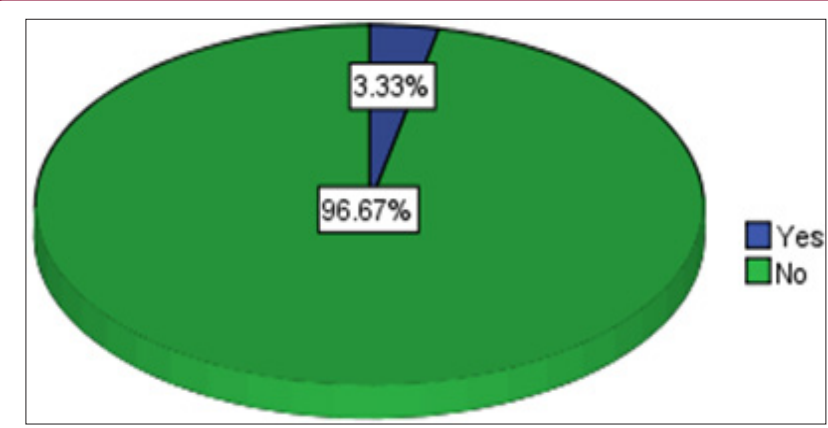

Figure 4: Difficulty in walking. 


\section{Discussion}

According to the financial Pakistan survey of blindness this medical condition is affecting $2-4.3 \%$ of Pakistani population. One of the main reasons of the blindness is the cataract. There are many reasons behind this condition. It can be age related in most of the cases, congenital and secondary to other causes. Surgery is the most effective and easy way to get rid of this situation and to stop visual impairment [23]. Progression to the aging process is highly linked to the development of cataract. In the present study majority of the respondents were suggested surgery and intra ocular lens was to be inserted in place of the cataract lens. Study done in Europe support the results of the present study which properly explain the total literature of the cataract and blindness and other complications related to the cataract [24,25]. Diabetics do not process glucose normally. The enzyme aldose reductase changes glucose to sorbitol through the polyol pathway. Sorbitol should be changed to fructose by the enzyme sorbitol dehydrogenase, but the sorbitol is produced faster than it can be converted to fructose, causing a buildup of sorbitol in the lens.

Accumulation of sorbitol leads to increased water within the lens, changing the lens fiber array and formation of sugar cataracts. Osmotic stress caused by the sorbitol accumulation 3 causes death of lens epithelial cells4 leading to the development of cataract. Increased glucose levels in the aqueous humor may cause chemical changes of lens proteins. This has negative effects upon the lens. Lenses of diabetics show an impaired antioxidant capacity, increasing the effect oxidative stress. For this reason, a healthy lifestyle to reduce the risk of developing diabetes over one's lifetime is highly recommended [26]. Smoking has been linked to cataract risk and is one reason eyecare practitioners have been more diligent to discuss smoking cessation with patients. One study reported that anyone with a history of smoking cigarettes was associated with an increased risk of age-related cataract. Current smokers had a higher risk of incidence. They found that former and current smokers were associated with nuclear and sub-scapular cataracts. Recently, another study found a significant dose-response relationship between smoking and the need for cataract extraction. Conversely, smoking cessation was associated with a decrease in risk that accumulated over time [27].

Various types of cataracts occur related to systemic disease. Inflammatory disorders causing uveitis may require recurrent use of topical or oral steroids. Common inflammatory disorders include ankylosing spondylitis, Crohn's disease, ulcerative colitis, juvenile idiopathic arthritis, Behçet's syndrome, and sarcoidosis. Repeated treatment of allergies using oral steroids or chronic use of topical or inhaled steroids may also cause posterior sub-scapsular cataracts in a presenile patient. Neurofibromatosis, a genetic disorder causing tumors to form on nerve tissue, is associated with cataract formation, as is Wilson disease, an inherited disorder associated with copper accumulation in the liver, ocular tissues, and other organs. Cataracts are now associated with syndromes such as Cohen syndrome, Degos disease, and Dubowitz syndrome. In some cases, the formation of cataracts may lead to initial diagnosis of a systemic condition $[28,29]$. Traumatic cataracts Trauma may result in clouding of the lens. Injury may be directly to the eye or indirectly, as seen with head trauma. It may be blunt or penetrating trauma, or it may be related to radiation exposure.

Changes may occur years or decades after the injury, and diagnosis is often made based upon appearance even if the patient is unable to report a traumatic event. A monocular, presenile cataract is a telltale sign of trauma. Blunt trauma is associated with a characteristic rosette or stellae-shaped opacification and often involves the posterior capsule. Penetrating injuries typically directly compromise the lens capsule, leading to cortical opacification at the injury site. Ocular surgery may also induce cataract formation. Retinal surgery, such as scleral buckling and vitrectomy, may result in presenile cataracts. To prevent blindness due to cataract routine medical checkups should be done. To prevent the further eye damage, risk factors should be controlled. Smoking should be avoided and diet high in anti-oxidants and carotenoids should be taken to prevent cataract in old age.

\section{Conclusion}

In the present study most of the respondents were suffering from age related cataract. Nuclear cataract was more prevalent among them. Majority of the patients had gone through the surgery and were facing difficulty in walking.

\section{References}

1. Allen D, Vasavada A (2006) Cataract and surgery for cataract. BMJ 333(7559): 128-132.

2. Lamoureux EL, Fenwick E, Pesudovs K, Tan D (2011) The impact of cataract surgery on quality of life. Current Opinion in Ophthalmology 22(1): 19-27.

3. Rao GN, Khanna R, Payal A (2011) The global burden of cataract. Current Opinion in Ophthalmology 22 (1): 4-9.

4. Pandey, Suresh K (2005) Pediatric cataract surgery techniques, complications, and management. Philadelphia: Lippincott Williams \& Wilkins 140(40): 20.

5. Allen D, Vasavada A (2006) Cataract and surgery for cataract. BMJ 333(7559): 128-32.

6. Gimbel HV, Dardzhikova AA (2011) Consequences of waiting for cataract surgery. Current Opinion in Ophthalmology 22(1): 28-30.

7. Lamoureux EL, Fenwick E, Pesudovs K, Tan D (2011) The impact of cataract surgery on quality of life. Current Opinion in Ophthalmology 22(1): 19-27.

8. Rao GN, Khanna R, Payal A (2011) The global burden of cataract. Current Opinion in Ophthalmology. 22(1): 4-9.

9. Pandey, Suresh K (2005) Pediatric cataract surgery techniques, complications, and management. Philadelphia: Lippincott Williams \& Wilkins 140(4): 20.

10. Reddy SC (1999) Electric cataract: a case report and review of the literature. European Journal of Ophthalmology 9(2): 134-138.

11. Ram Jagat, Gupta Rohit (2016) Petaloid Cataract. New England Journal of Medicine 374(18): 22.

12. Sliney DH (1994) UV radiation ocular exposure dosimetry. Doc Ophthalmol 88(3-4): 243-254.

13. Lipman RM, Tripathi BJ, Tripathi RC (1988). Cataracts induced by microwave and ionizing radiation. Surv Ophthalmol 33(3): 200-210. 
14. Hejtmancik, Smaoui (2003) Molecular Genetics of Cataract, Genetics in Ophthalmology. Karger Medical and Scientific Publishers 37: 67-82.

15. Yanoff Myron, Duker, Jay (2009) Ophthalmology. Elsevier Health Sciences

16. Christen WG, Manson JE, Seddon JM, Glynn RJ, Buring JE et al. (1992) A prospective study of cigarette smoking and risk of cataract in men. JAMA 268(8): 989-993.

17. Wang S, Wang JJ, Wong TY (2008) Alcohol and eye diseases. Surv Ophthalmol 53(5): 512-525.

18. Wei L, Liang G, Cai C, Lv J (2016) Association of vitamin C with the risk of age-related cataract: a meta-analysis. Acta ophthalmologica 94(3): 170-176.

19. Weatherall M, Clay J, James K, Perrin K, Shirtcliffe P et al. (2009) Doseresponse relationship of inhaled corticosteroids and cataracts: a systematic review and meta-analysis. Respirology 14(7): 983-990.

20. Almony Arghavan, Holekamp Nancy M, Bai Fang, Shui Ying Bo, Beebe David (2012) Small-gauge vitrectomy does not protect against nuclear sclerotic cataract. Retina 32(3): 499-505.

21. Shui Ying Bo, Holekamp, Nancy M, Kramer Benjamin C, Crowley Jan R et al. (2009) The Gel State of the Vitreous and Ascorbate-Dependent Oxygen Consumption. Archives of Ophthalmology 127(4): 475-482.

22. Jalil A, Steeples L, Subramani S, Bindra MS, Dhawahir-Scala F et al (2014) Microincision cataract surgery combined with vitrectomy: a case series. Eye 28(4): 386-389.
23. Ma L, Hao Z, Liu R, Yu R, Shi Q, et al. (2013) A dose-response metaanalysis of dietary lutein and zeaxanthin intake in relation to risk of age-related cataract. Graefe's Archive for Clinical and Experimental Ophthalmology 252(1): 63-70.

24. Hayashi R (2014) The Effects of Lutein in Preventing Cataract Progression. In Babizhayev 317-326.

25. Mam Li DWC, Kasus Jacobi A, Žorić L, Alió JL (2015) Studies on the Cornea and Lens. Oxidative Stress in Applied Basic Research and Clinical Practice, pp. 317-326.

26. Davis JC, McNeill H, Wasdell M, Chunick S, Bryan S (2012) Focussing both eyes on health outcomes: Revisiting cataract surgery. BMC Geriatrics 12: 50 .

27. Peter Naeser, Brolin SE (2009) Influence of glucose, fructose and aldose reductase inhibition on retinal sorbitol metabolism. Acta Ophthalmologica 69(5): 591-595.

28. Krishnaiah S, Vilas K, Shamanna BR (2005) Smoking and its association with cataract: results of the Andhra Pradesh Eye Disease Study from India. Invest Ophthalmol Vis Sci 46(1): 4658-4665.

29. Elena Prokofyeva, Alfred Wegener, Eberhart Zrenner (2013) Cataract prevalence and prevention in Europe: a literature review. Acta Ophthalmologica 91(5): 395-405.

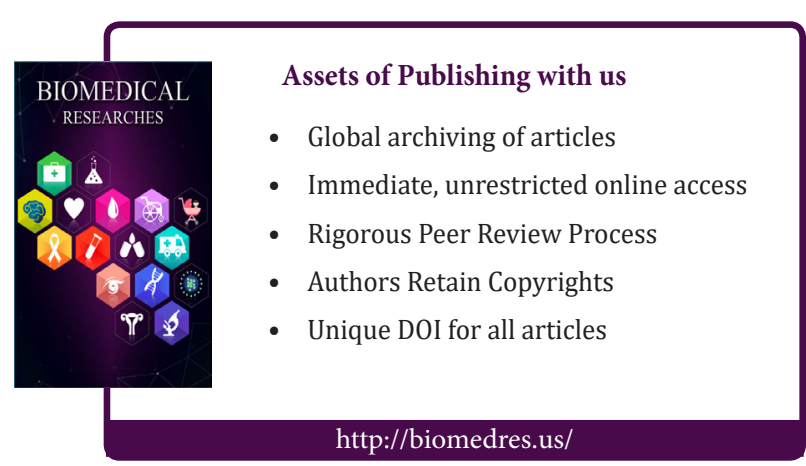

